\title{
Medical Ethnobotany of the Yucatec Maya: Healers' Consensus as a Quantitative Criterion ${ }^{1}$
}

\author{
Anita ANkli, Otto Sticher, AND Michael HeinRich ${ }^{2}$
}

\begin{abstract}
Ankli, Anita; Otto Sticher (Department of Pharmacy, Swiss Federal Institute of Technology (ETH) Zurich, Winterthurerstrasse 190, CH-8057 Zürich, Switzerland), and Michael Heinrich (Institute of Pharmaceutical Biology, Schänzlestr. 1, Albert-Ludwigs-University, D-79104 Freiburg, Germany). Medical Ethnobotany of the Yucatec Maya: Healers' Consensus as a QuANTITATIVE Criterion. Economic Botany 53(2):144-160, 1999. There is an urgent need to obtain information on the relative importance of a taxon used medicinally as compared to others within the same culture. This was achieved through a documentation of the current indigenous medical uses of 320 species in three Yucatec Maya communities during 18 months of fieldwork. The 1549 individual reports documented were divided into nine groups, which classify indigenous uses. The frequency of usage of the individual plants reported was employed in the analysis of the ethnobotanical importance of the respective taxa. Species cited more frequently in a group of indigenous uses are regarded to be of greater ethnobotanical importance than those cited only by a few informants. In order to obtain information on possible biological, pharmacological and toxicological effects of some particularly important species, the scientific literature on these taxa was evaluated systematically. The study is the basis for phytochemical and pharmacological evaluations of the traditional uses.
\end{abstract}

Etnobotanica Medica de los Mayas Yucatecos: Consenso de Curanderos como Criterio CuANTITATIVO. Se considera esencial la documentación de la importancia relativa que un taxon de uso medicinal tiene, en comparación con otros taxones dentro de una misma cultura. Con este propósito se realizó un estudio etnobotánico de 18 meses, investigando el uso de 320 especies en tres comunidades Mayas del Estado de Yucatán (México). Se documentaron 1549 usos indígenas, que se clasificaron en 9 grupos. Se utilizó el número de usos indígenas para determinar la importancia relativa de cada especie; así, las especies medicinales que fueron citadas con mayor frecuencia se consideran las de mayor importancia, mientras que las especies citadas con menor frecuencia son las de menor importancia. Para evaluar los usos indígenas se obtuvo información sobre efectos biológicos, farmacológicos y toxicológicos de las especies, através de una revisión sistemática de la literatura científica. Este estudio es la base para la selección de plantas que se evaluarán en estudios fitoquímicos y farmacológicos.

Key Words: Yucatec Maya traditional medicine; indigenous medicinal plants; ethnobotany; evaluation of indigenous uses; quantitative method; Yucatan (Mexico).

In recent years we and others have called attention to the lack of information on the relative importance of a medicinal plant (or other useful plant) within a culture and the need for comparing the uses of plants interculturally (Heinrich, Rimpler, and Antonio B. 1992; cf. Etkin 1994; Moerman 1996). A constructive method to obtain such information is the quantification of indigenous uses (Phillips 1996) which is appro-

\footnotetext{
${ }^{1}$ Received 20 February 1997; accepted 15 November 1998 .

${ }^{2}$ Correspondence to:

heinrich@vitex.biologie.uni-freiburg.de; fax. $++49-$ 761-203-2803.
}

priate when the relative importance of each use is similar, as with pharmaceutical preparations such as medicinal plants used for different types of illnesses. Accordingly, this paper is the third in a series on Mexican indigenous medicinal plants (Frei, Sticher, and Heinrich 1998 on the Isthmus Sierra Zapotecs, Oaxaca; Weimann and Heinrich 1997 on the Nahua of the Sierra de Zongolica, Veracruz). An additional goal of these studies has been the selection of plants for phytochemical and biological/pharmacological studies (Bork et al. 1997; Kato et al. 1996).

Therefore all three of our ethnobotanical studies use similar methodologies (see also Methods): (1) Specialists in medicinal plants (for ex- 
ample, healers, midwives, herbalists) were interviewed during 14-18 months of fieldwork and the use-reports of each informant recorded. (2) The use of the plants is grouped into 9-10 categories.

The principal groups are similar in all three studies: gastrointestinal disorders, illnesses of the skin (mostly infections and subsequent inflammatory reactions), respiratory disorders, gynecological (and andrological) conditions. Since there exist ethnobotanical differences between the three ethnic groups, 5-6 additional groups were formed, which are only used in one or two of the studies, for example, plants used for bites and stings of poisonous animals (only Maya), opthalmological illnesses (Maya and Zapotec), and culture bound syndromes (Nahua and $\mathrm{Za}$ potecs).

This comparative method facilitates the selection of medicinal plants for phytochemical and biological/pharmacological studies, and is useful in determining the ethnobotanical importance of a particular plant in contrast with others in the same use category (Heinrich et al. 1998). There have been several other approaches to establish quantitative criteria for the relative ethnobotanical importance of plants (Berlin and Berlin 1996; Friedman et al. 1986; Johns, Kokwar, and Kimanani 1990; Phillips 1996). The method of Berlin and Berlin is of special relevance to ours. We both used a similar approach, however, they interviewed the general population and thus recorded and evaluated an enormous set of positive responses (30 000, Berlin and Berlin 1996: 81-82). Their method requires a considerable investment in research funds and personnel. The method presented here is tailored to allow for the assessment of the relative cultural, medical and, consequently, also the socio-economical importance of plants employed by medical specialists in an ethnic group and is feasible with a lower input of resources.

A detailed study of Yucatec Mayan medicinal plant use seemed to be of particular relevance. Traditional forms of treating illness among the Yucatec Maya of Mexico who still use locally available plant resources are of considerable importance. Their medical system and knowledge is without doubt a vital part of their culture (Redfield and Villa R. 1990 [orig. 1934]; Roys 1931; Standley 1930; Steggerda and Korsch 1943). Although many aspects of Mayan ethnobotany have been addressed in detail, such as ethnoecology (Herrera 1994; Humphries 1993; Terán and Rasmussen 1994) and plant nomenclature (Barrera M., Barrera V., and López F. 1976; Sosa V. et al. 1985), only a few reports exist on the medicinal plants currently used. For example, Arnason et al. (1980) studied a Mayan community in Belize, Comerford (1996) a Mayan community in lowland Guatemala, and Alcorn (1984) the Huastec Maya. In addition, some theses have been written on the topic and booklets are distributed locally or regionally (Cardeña V. 1985; Pulido S. and Serralta P. 1993; cf. Mendita and Amo 1981 and Morton 1981; Argueta V. 1994).

Our study thus has a twofold purpose: (1) to systematically record the use of medicinal plants in communities of the Yucatec Maya in Mexico, and (2) to form the basis for comparative studies on Mexican Indian medicinal plant use.

\section{BACKGROUND \\ YuCATÁN AND THE MAYA}

The peninsula of Yucatán forms the easternmost part of Mexico which is divided politically into three states: Yucatán, Quintana Roo and Campeche. The northern parts of Guatemala and Belize are also part of the peninsula and have a high percentage of Lowland Mayan speakers (Fig. 1). The peninsula is an enormous limestone plateau with an average altitude of less than 100 $m$ a $s$. No surface rivers exist in the northern part of the peninsula. The most important water sources are cenotes (natural sink holes formed by the collapse of the limestone surface over the ground). The annual rainfall is highest in the southeast (1300-1400 mm) and diminishes towards the north and northwest $(400 \mathrm{~mm})$. The natural vegetation in the southeast is tropical rainforest, while in the extreme northeast it is low tropical deciduous forest. Due to the low latitude, the climate is warm and in the southeast, humid.

For more than a millennium the civilizations of the Ancient Maya flourished on the peninsula and adjoining regions (Koehler 1990). Currently 600000 persons, or $36 \%$ of the total population of the peninsula, are mono- or bilingual speakers of Maya (Pfeiler 1995). Even though the influence of outside forces has been enormous, the Yucatec Maya still retain a large number of ancient traditions and have opposed the cultural dominance of the Spaniards and the surrounding 

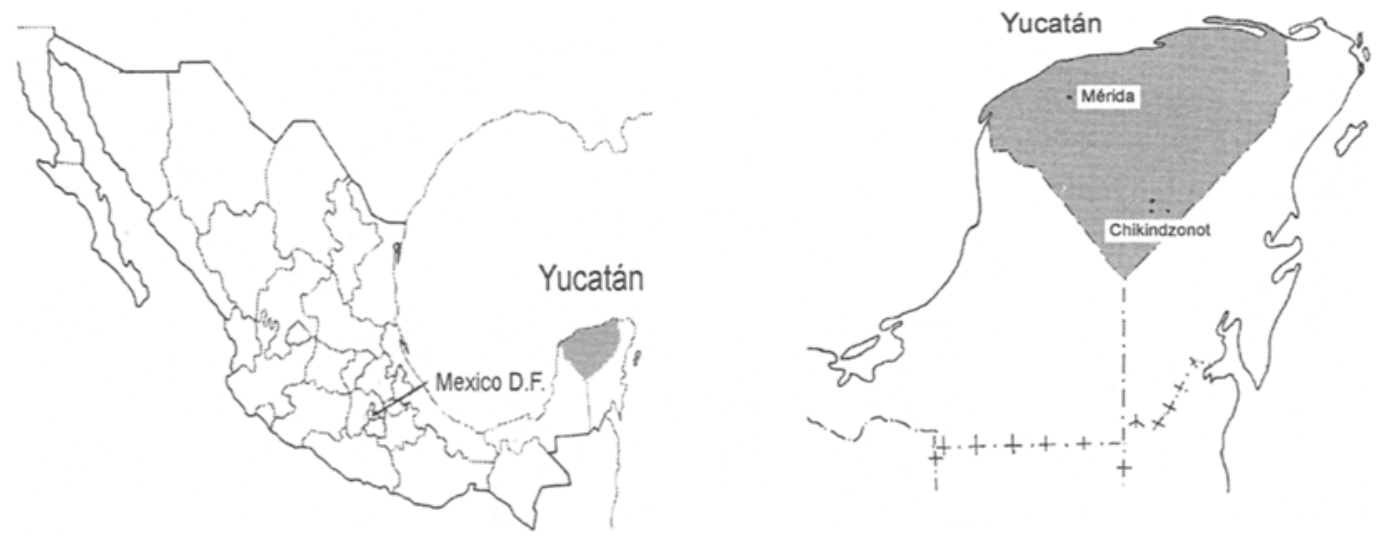

Fig. 1. Region of fieldwork.

national Mexican culture. The so-called "caste war" of the last century which involved the Maya, is just one example of the resulting conflicts (Orosa D. 1991).

Yucatec Maya language belongs to the mayance (or mayoide) subfamily of Macropenutian. Maya vowels and consonants are generally pronounced as in Spanish. A glottal stop ['] is known and glottalized consonants are frequent. In this article, Maya words are transcribed after Barrera M., Barrera V., and López F. (1976).

\section{The Communities}

This study was conducted in the communities of Chikindzonot $\left(20^{\circ} 20^{\prime}\right.$ degrees latitude north, $88^{\circ} 29^{\prime}$ degrees west, 30-40 $\mathrm{m}$ a s l) and the neighboring Ekpetz and Xcocmil south of the city of Valladolid in the southeastern part of the state of Yucatán. These communities were selected because of a high rate of speakers of Yucatec Maya, the well known cultural conservatism in this region and the high number of healers known (Orosa D. 1991; Tuz, Valladolid, pers. comm.)

Average annual temperature in the area is $25.7^{\circ} \mathrm{C}$ and it has an average annual precipitation of $1220 \mathrm{~mm}$. According to Duch (1988) the climatic subtype is Aw $1^{\prime \prime}\left(x^{\prime}\right)\left(i^{\prime}\right)$ g, i.e., a hot subhumid climate with rain from May to October $(980 \mathrm{~mm})$ and little thermal oscillation throughout the year. The vegetation is characterized as a median semideciduous forest with an average height of $10-20 \mathrm{~m} .50$ to $75 \%$ of the species remain deciduous during the dry season. Typical tree species include Acacia pennatula (Schlecht. \& Cham.) Benth., Bursera simaruba Sarg., Cae- salpinia gaumeri Greenman, Cochlospermum vitifolium Willd. ex Spreng., Enterlobium cyclocarpum Griseb, Guazuma ulmifolia Lam., Gymnopodium floribundum Rolfe, Mimosa bahamensis Benth. and Vitex gaumeri Greenman (Salvador F. and Espejel C. 1994).

The communities of Chikindzonot and Ekpetz have 1500 and 800 inhabitants, respectively (INEGI 1990). The whole municipio of Chikindzonot has 2750 inhabitants. $56 \%$ of the persons older than 15 yrs. are literate and one third of those older than 5 yrs. are monolingual speakers of Maya and the remainder bilinguals. The economy is based on subsistence agriculture (mostly maize, beans and squash) and on the production of honey, fruit (watermelon and citrus fruits) and cattle breeding. Hunting is still practiced regularly, especially by younger men. Handicraft articles (hammocks and huipiles-female dress) are sold in the market of Valladolid. No detailed anthropological monograph on the Maya of this area is available, but the community of Chan Kom, which was first studied by Redfield and Villa R. 1990 [orig. 1934], is only $27 \mathrm{~km}$ to the north.

\section{Health and Healing}

According to the unpublished data of the local health authorities and our surveys it is apparent that gastrointestinal disorders (frequently diarrhea and-in younger children-as a result thereof, dehydration) and respiratory illnesses are major health problems. Infected wounds and other inflammatory skin diseases are also common. Bites from poisonous snakes (e.g., tsabcascabel-Crotalus durissus L.) are feared, yet 
only a few cases have been recorded in recent years. Chronic and infectious eye diseases are frequent. Diabetes is now considered an important health problem by the local health authorities, and informants often claim to suffer from this illness. Most of the medicinal plants sold in the markets of Valladolid and Mérida promise to alleviate diabetes or to function as diuretics.

The best known group of healers are h-men (Maya for knowledgable healer or prayer maker), who are not only healers but also specialists in religious rites and who perform ceremonies addressing the rain-god to ask for protection of the milpa or the community. $\mathrm{He}$ or she is the owner of a sastun, a stone used for divining. Midwives and herbateros (specialists in medicinal plants) form another group of healers. Those of the latter group are generally proficient in treating broken bones and thus work as hueseros. Massages are given by another group of healers - the sobadores-and by midwives. All these groups of healers make extensive use of medicinal plants. Some groups largely use these plants as part of empirical medications, while others, in particular, the h-men, also use the plants for ritual purposes.

An outpatient clinic run by the SSA (Secretaría de Salud y Asistencia) and staffed with a pasante (a medical student in her or his last year of training) and a mestizo nurse provides biomedical health care, but for most conditions people still prefer the Mayan healers. In 1993/1994 the pasante (a woman) was called only once to help during a delivery.

\section{Methods}

Ethnomedical and ethnobotanical data were collected mostly in the two communities of Chikindzonot and Ekpetz from February 1994 until May 1995 and September/October 1996. Specialists in medicinal plants and/or healers of the different regions were interviewed. This paper is based on structured and unstructured interviews with 40 healers. Twelve healers aged between 29 and 71 , who represent all the groups of specialists mentioned above, were interviewed frequently and contributed a large share of the information presented here. Together with informants we collected plant materials that were cited as medicinal. During meetings of groups of indigenous healers, we conducted unstructured interviews on the medicinal plants and methods of treatment. We thus obtained information on the use(s), preparation(s), plant parts used, application(s) and properties of the plants as well as descriptions of illnesses and treatments, which we compiled into ethnobotanical data sheets.

Voucher specimens were collected and are deposited at the National Herbarium of Mexico (MEXU), the Herbarium of the "Centro de Investigación Cientifíca de Yucatán" (CICY) in Mérida, the Instituto Nacional Indigenista (INI) in Valladolid (both Yucatán), the ETH Zurich (ZT) and the Institut fuer Pharmazeutische Biologie in Freiburg, Germany (collection numbers A. Ankli, AANK1-540). Plants were identified by comparison with authentic specimens and in some cases with the assistance of specialists at CICY and MEXU.

Reports of ethnobotanical uses were documented for each plant. The healers were asked to demonstrate the plants which they currently use or which they had used. In order to analyze the data, the plants were arranged into nine classes of indigenous use and for each class the data were quantified by adding up the individual reports on the uses of each plant. Species were then ranked according to the number of reports of use. Plants in these groups which were cited as medicinal by four (in case of the gastrointestinal illnesses by five) or more informants are presented here. A literature search in BIOSIS PREVIEW (and in selected cases, also in NAPRALERT and Chemical Abstracts) was performed for the plants most frequently cited in order to obtain data on phytochemistry and on biological and pharmacological effects of the respective taxa.

\section{Results and Discussion}

Illness according to the Yucatec Maya may be classified as being humorally "hot" or "cold" (Redfield and Villa R. 1990 [orig. 1934]). Imbalance of the body, for example, caused by consuming something "cold" when a person is in a "hot" state may lead to illness. Diarrhea, for example, is considered to be a "cold" illness, while dysentery (bloody diarrhea) is classified as "hot." This classificatory system is also central during and after childbirth. After giving birth, a woman is considered to be in a "cold" state and therefore is not allowed to eat certain foods such as pork, beef and foods which contain much grease. The "hot/cold" classification of the Yucatec Maya was recorded by Redfield 


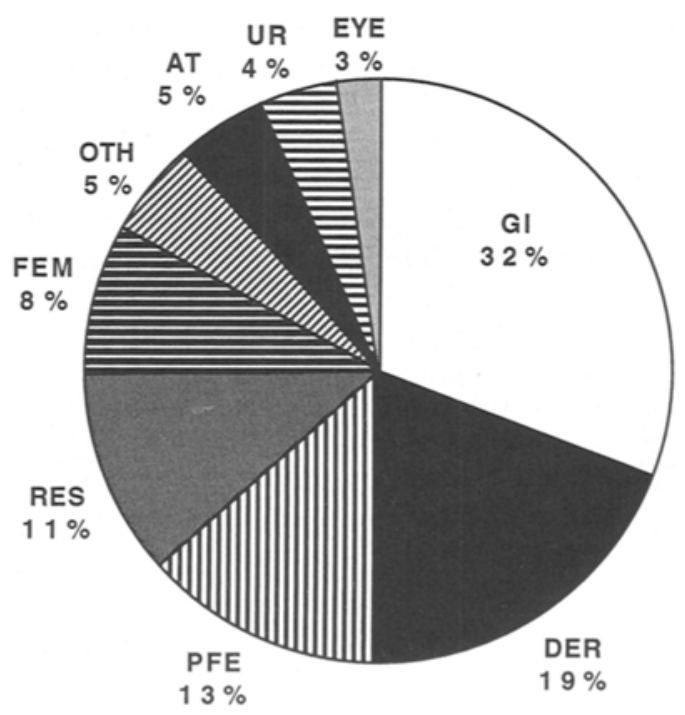

Fig. 2. Quantitative ethnobotanical analysis of the nine groups which classify the indigenous use reports (total number of species: $320 ; n=1549$ use reports; AT $=$ counteract bites and strings of venomous animals; DER = dermatological conditions; EYE = illnesses of the eyes; FEM = women's medicines; $\mathrm{GI}=$ gastrointestinal disorders; $\mathrm{PFE}=$ illnesses associated with pain and/or fever; OTH = other uses; RES = respiratory illnesses; UR $=$ urological problems).

and Villa R. 1990 [orig. 1934] and was reported in the sixteenth century (Lopez A. and Viesca T. 1984; Villa R. 1981). Nonetheless, the humoral system does not encompass the entire medical system of the people we worked with. Many uses of plants are based on personal experience or oral transmission within the family.

Illness may be caused by "wind" (i.e., by bad air which enters a weak person's body), witchcraft or nocturnal birds and bats. Younger informants now refer to microbes as another causative agent of disease. When a person is treated, ritual and empirical plant use are closely connected. If the illness requires it, the healer includes a ritual cleansing ceremony (santigua or limpia). The healer asks God for help and for the permission to cure.

In this paper we concentrate on the medicinal use of plants among the Yucatec Maya. We document a total of 1549 individual responses to queries concerning 320 plant species. These responses were grouped into nine categories of indigenous use (Fig. 2). We constructed all major and most of the lesser categories to coincide with indigenous classifications (cf. Berlin and
Berlin 1996). A few of the smaller categories are combinations in order to accommodate, for example, the various forms of chronic and acute "pain" and illnesses associated with a rise of body temperature. One residual group ("other uses") is also included. Yucatec Maya healers are well acquainted with the causes and detectable signs (symptoms) of illness. It is no surprise then that the groups relate to the organs affected during a certain illness (gastrointestinal tract, skin, respiratory system).

The largest number of species and individual use-reports (Fig. 2) were obtained for gastrointestinal disorders. This group of disorders was second only to dermatological illnesses in the studies of the Isthmus Sierra Zapotecs and Nahua of the Sierra de Zongolica (Frei, Sticher, and Heinrich 1998; Weimann and Heinrich 1997) in terms of the number of use-reports and among the Zapotecs in terms of the number of species used. Among the Nahua it was the group with the largest number of species recorded. Dermatological problems are the second largest group among the Yucatec Maya. It is noteworthy that these two groups of uses are prominent in all studies mentioned. Also, respiratory illnesses yield a large number of use-reports and 87 taxa-the third largest number. Of particular importance according to the Yucatec Maya are plants used in the treatment of bites from venomous animals, especially snakes $(4.8 \%$ of all use-reports). In the following, the principal species used by the Yucatec Maya for each of the 9 groups are discussed. The ethnobotanical data are summarized in Tables 1-7.

\section{Gastrointestinal Disorders}

In this group 147 species with 476 use-reports were documented. Diarrhea is a frequent condition, especially in children. Other illnesses, included in this group, are gastrointestinal cramps, vomiting and mal de ojo (evil eye, no Yucatec Maya term used). The latter is an illness caused by a person, who looks at a child with a so called "strong glance." A drunken person, a women during menstruation and people born on Tuesday or Friday are particularly likely to cause this illness. Its signs are various gastrointestinal symptoms, particularly "green" diarrhea, gastrointestinal cramps and vomiting. To cure the ill person, the one who has caused the illness has to embrace the patient or to show her/his care in another way. Additionally herbal prepa- 
rations are used. Another important illness is tip'te' (cirro). It is an "organ" reported to sit below the umbilicus. If a person has eaten inadequate food or after having carried something heavy the tip'te' palpitates and is dislocated (cf. Berlin and Jara 1993 on a similar concept in Highland Chiapas). Treatment consists mostly in circular massages around the navel and in drinking a decoction of tip'te' ak (Microgramma nitida).

The three members of the genus Mentha-M. piperita, $M$. citrata (leaves/aerial parts) and $M$. arvensis (roots and leaves), which are widely used to treat vomiting and to a lesser degree diarrhea (Table 1), are widely known and effective antispasmodics of European origin (Haensel et al. 1993). Abrus precatorius is used only externally for diarrhea and the evil eye in the form of baths and therefore is not discussed further. Manilkara zapota (mostly bark, also roots and fruits) is employed for diarrhea and is best known for yielding chicle-a latex rich in polyisoprenes. The bark is also known to be rich in tannins (Hegnauer 1973:296), but no data on their structure have been published (Hegnauer 1990:498). While a huge number of publications on the production and use of the latex are available, no pharmacological information relating to the indigenous uses is available. The relevant reports on the genus Aristolochia were recently summarized (Weimann and Heinrich 1997). No data are available to substantiate the Mayan uses for diarrhea. Callicarpa acuminata (shoots) is a Yucatec Maya remedy for mal de ojo associated with green diarrhea and dysentery. The genus Callicarpa is one of the few in the Verbenaceae (s.1.) in which no iridoids could be found (Falk 1992). Instead diterpenoids as well as triterpenoids and flavonoids were reported from the genus (Glasby 1991). Whether these exert any relevant pharmacological effects is unknown. Lippia alba, L. stochadifolia (leaves) and related species are used in many different cultures for gastrointestinal disorders, the Yucatec Maya value the species to induce vomiting. Many species of this genus are rich in essential oil (Lippia alba $>1 \%$; Hegnauer 1973:668) and thus may act as carminatives.

Roots of Dorstenia contrajerva are used for a variety of gastrointestinal conditions, chiefly for stomach ache, "air in the stomach" and gastrointestinal cramps. Similar uses of $D$. drako are reported from the Istmo Sierra Zapotecs (Frei,
Sticher, and Heinrich 1998). Furanocoumarins are known from $D$. contrajerva (Terreaux et al. 1994), but no data are available on its pharmacological effects. Pimenta dioica is rich in essential oil (with approx. 35\% eugenol and 40 $45 \%$ eugenol methylether), has a wide use for unspecified gastrointestinal problems (List and Hoerhammer 1977) and may well be an adequate treatment of "air in the stomach." A central nervous depressant effect of the aqueous (and to a lesser degree of the ethanolic) leaf extract applied i.v. was recently shown as part of a hippocratic screening (Suárez et al. 1997). Psidium guajava (leaves and sometimes also root) is used for diarrhea and dysentery. These uses are also described by Aguilar et al. (1994), Weimann and Heinrich (1997) and Girón et al. (1991). The leaves are mentioned in Farmacopea Mexicana as astringents. Pharmacological tests on the leaves showed activity against $E$. coli and spasmolytic effects (Berlin and Berlin 1994; Weimann and Heinrich 1997) which reportedly are due to a calcium-antagonist effect of quercetin glycosides (Morales et al. 1994). All plant parts are rich in phenols, especially hydrolyzable tannins and proanthocyanidins (Okuda et al. 1987). Teloxys ambrosioides (syn.: Chenopodium ambrosioides) is another widely used Mesoamerican species employed as antiemetic, antiparasitic and antidiarrhetic. Ascaridol is a well-known monoterpene with antiparasitic effects, but also with undesirable side effects (Hegnauer 1964:421).

Artemisia ludoviciana ssp. mexicana (leaves) has a long tradition of use in Mesoamerica. The Yucatec Maya value this plant for treating vomiting. It is rich in sesquiterpene lactones, but no data on anti-emetic effects are available (Bork et al. 1996; Heinrich 1996). Ruta chalepensis (leaves) is known from many cultures and widely used as antispasmodic. It is prominent for its content of a large number of different alkaloids and furanocoumarins, is a common abortifacient and has severe side effects (Haensel et al. 1993. 1994; Heinrich 1989).

\section{Dermatological Conditions}

In this group 302 use-reports referred to 150 species. Small cuts, infections and other skin problems are frequent and generally treated at once with plants (150 species with 302 use-reports) that are readily available. Other frequent health problems are pimples (saa sak' winkli), 


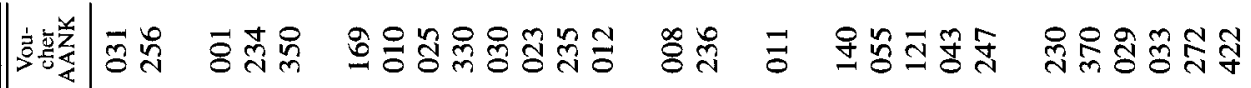

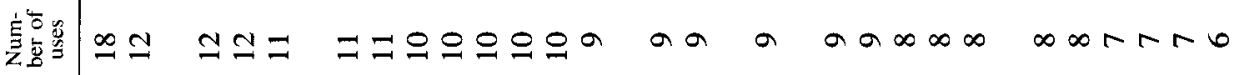

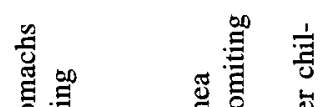

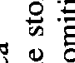

s옳

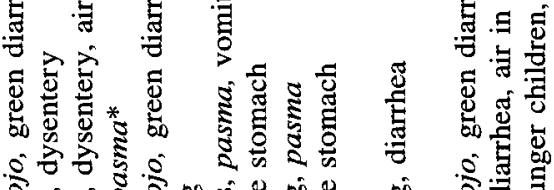

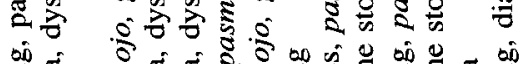

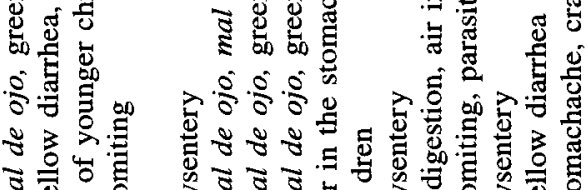

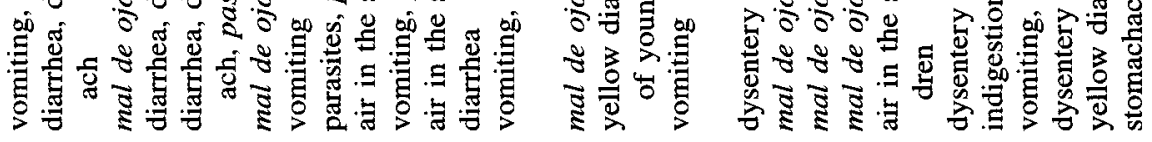
寄

$\geq \geq$

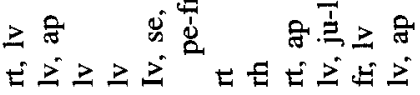




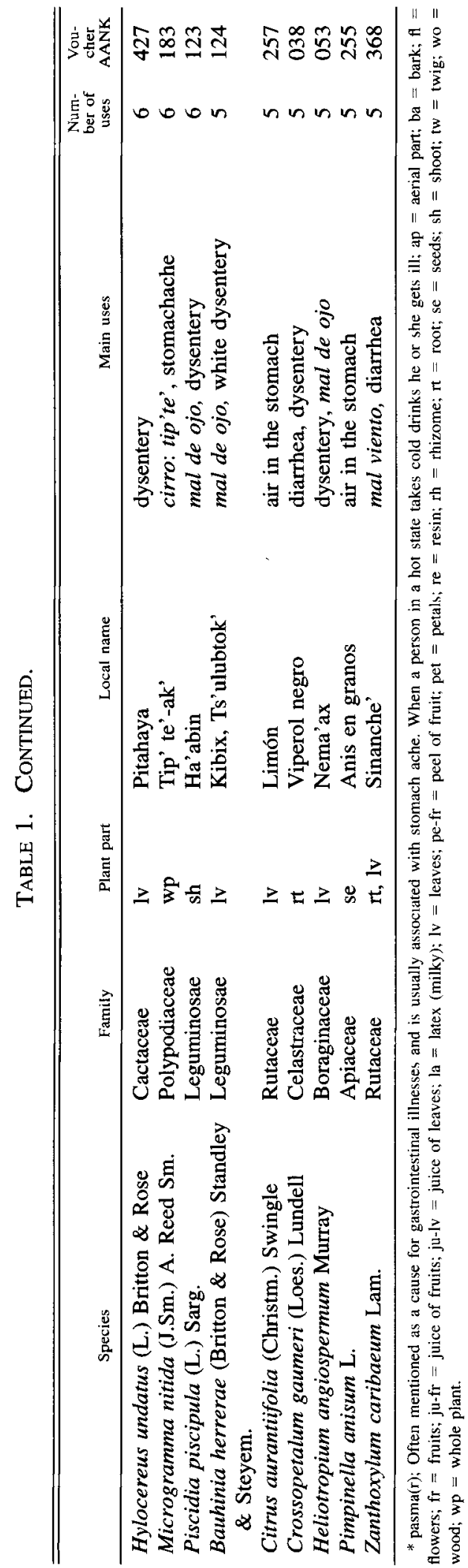

warts and scabies. The rootstock of Anredera vesicaria is used as a wound dressing and for infections (Table 2). Little chemical information is available on the genus. Only a retrochalcone was isolated from another species of this genus (Calzado et al. 1990). Calea urticifolia, another remedy for pimples, contains sesquiterpene lactones and is an effective inhibitor of the transcription factor NF- $\kappa \mathrm{B}$, which controls genes responsible for the inflammatory responses of the body (Borges de C. et al. 1981; Bork et al. 1997). Crossopetalum gaumeri is known to have antibacterial and cytotoxic effects (see Plants Used to Counteract Venomous Animal Bites and Stings). Diospyros anisandra is employed in the treatment of pimples and scabies. Of the approximately 240 species in this genus, only $D$. $k a k i$ and $D$. mollis were investigated in greater detail by various groups. Triterpenes (lupeol, betulin, betulinic acid) and naphtoquinones are widely distributed in the genus. $D$. anisandra has yet to be studied (Hegnauer 1989:403-407). The leaves of Ocimum micranthum and Salvia micrantha are both used for infections and inflammation of the skin. Neither species has been studied in detail, but $O$. micranthum especially merits further study (Heinrich 1992). Species of both genera are rich in essential oil; in Salvia spp. neo-clerodane diterpenoids were frequently reported as bioactive compounds (RodríguezHahn et al. 1995). The use of Kalanchoë integra (leaves) as a topical anti-inflammatory seems to be based on the succulent nature of the leaves. Whether the plant exerts any specific anti-inflammatory effect is unknown. Leaves of $P_{s i-}$ dium sartorianum are used for the same conditions. While no specific data for this taxon are available, species of this genus are rich in hydrolyzable tannins and proanthocyanidins in all plant parts (Okuda et al. 1987), and thus may have some anti-infective effects. No pharmacological data are available to substantiate the claims in the case of Samolus ebracteatus.

\section{Illnesses Associated with Pain AND/OR FEVER}

This category (see Table 3 ) is rather diverse and includes plants (112 species with 204 usereports) that are used for chronic or acute pain and fever. These ailments are commonly treated with external appplications of species known to be rich in essential oils (e.g., Ruta chalepensis, leaves, aerial parts, locally known as an external 


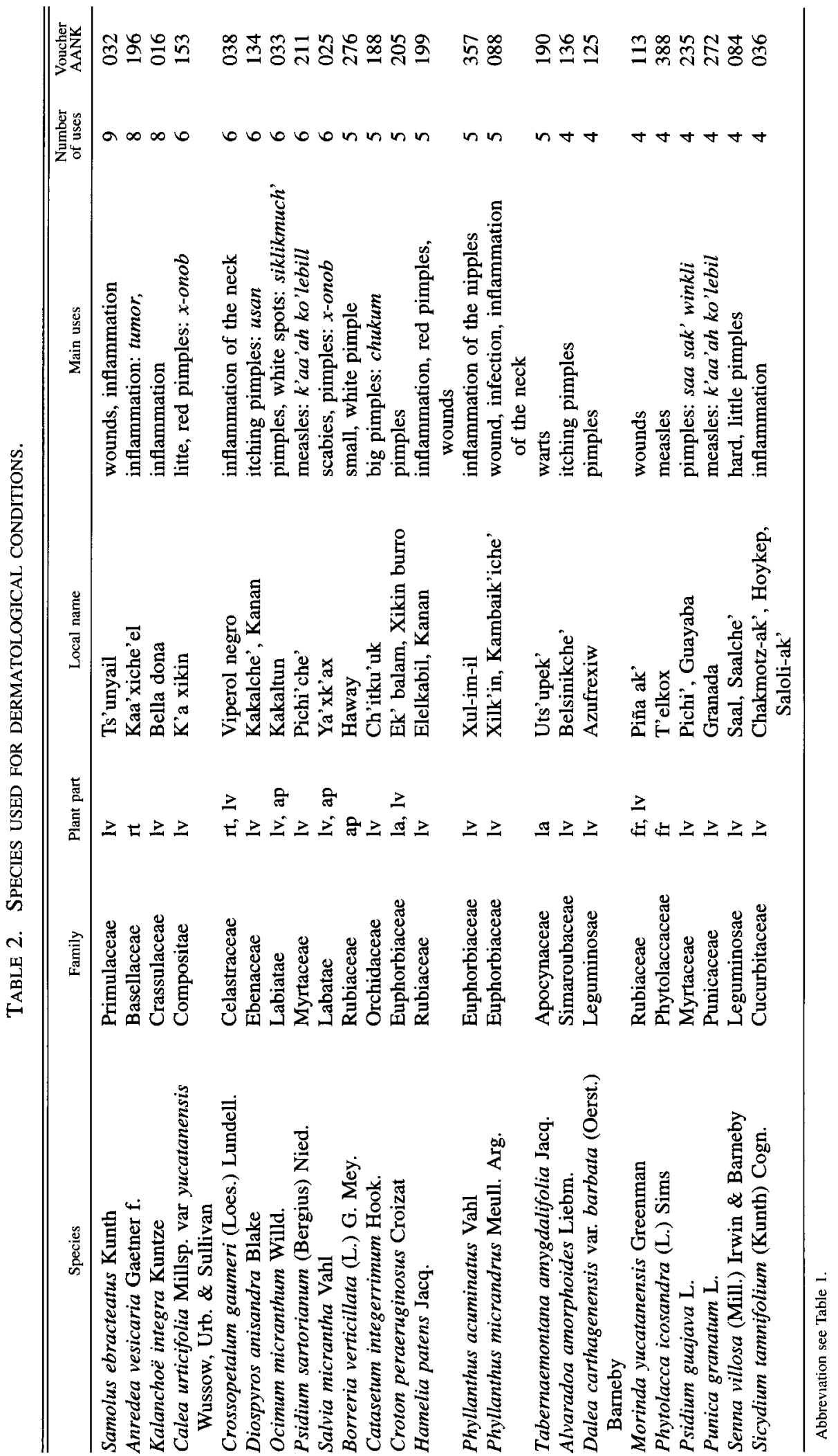




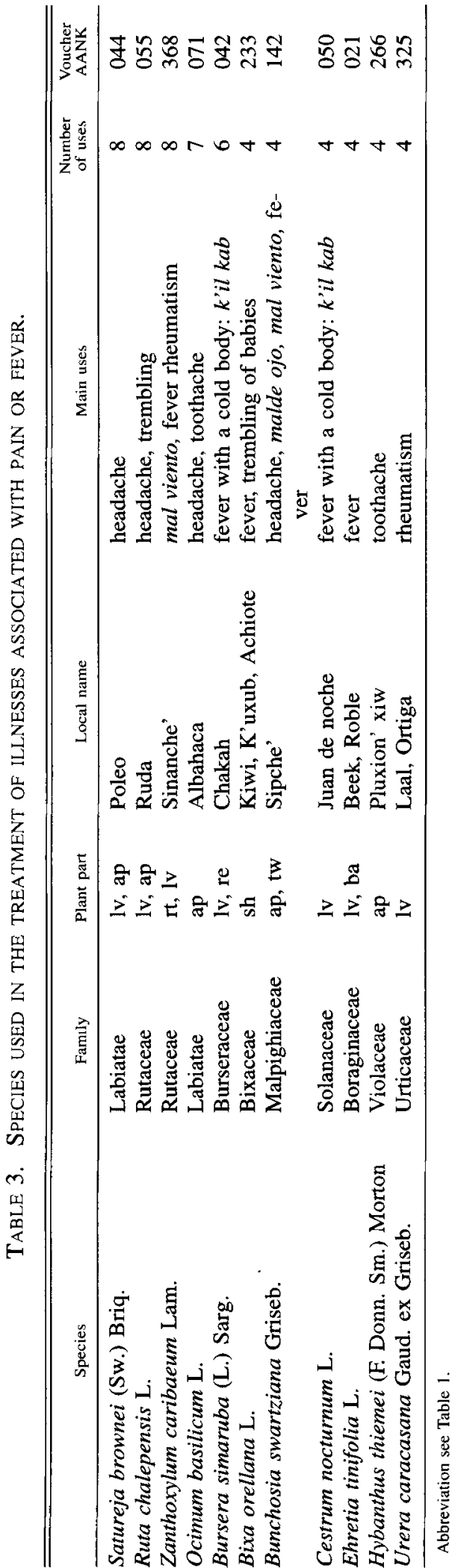

remedy for headache, see above). Illnesses associated with fevers are generally treated with baths. Pain is generally treated with plasters and other external applications.

Satureja brownei [syn.: Micromeria brownei (Sw.) Benth.; leaves] is used in the form of baths for headaches and has a diverse range of uses among many other peoples in Central America, the Caribbean and Mexico (Heinrich 1992). Essential oil and methylated flavones are found in taxa from this genus (Tomas B., Husein, and Gil 1988). The ethanolic leaf extract showed inhibitory activity against Staphyllococcus aureus and Streptococcus pyogenes in a screening of 68 Guatemalan plants (Cáceres et al. 1991), but no relevant pharmacological data are available on the species used and therefore it is not possible to evaluate the Mayan use. Zanthoxylum caribaeum (roots) is widely known among the Yucatec Maya as a cure to rheumatism, headache, and "mal viento." Many species of this large genus with approximately 200 species have been studied phytochemically and/or pharmacologically in detail. Characteristic are benzyl isochinolin alkaloids, lignans, coumarins and unusual amides (Hegnauer 1990:449-455). Since the plant is employed externally in ritual cleaning ceremonies, an evaluation of the indigenous claims goes beyond the scope of this study.

Ocimum basilicum is a well known species rich in essential oil $(0.5-1.5 \%)$ introduced into numerous indigenous medical systems of the Americas (Heinrich 1992). Analgesic or antibacterial effects would be of relevance for the Yucatec Maya use in case of toothache, and there is some information on antibacterial effects of the essential oil (Heinrich 1989; List and Hoerhammer 1977). Leaves of Bursera simaruba are exclusively employed externally for fever (baths). The genus is rich in essential oils. Triterpenes, lignans and procyanidies are also found (Khalid 1983), but are probably of no relevance to the use discussed here. Its external use for fever is known from other parts of Mexico and seems to be partially based on the aromatic smell of the leaves, resin and bark (Heinrich 1989).

\section{RESPIRATORY ILLNESSES}

The species in this group (87 with 177 usereports) are locally used for cough, bronchitis and "asthma" (Table 4). The latter illness is described as a longlasting wheezing, caused by 


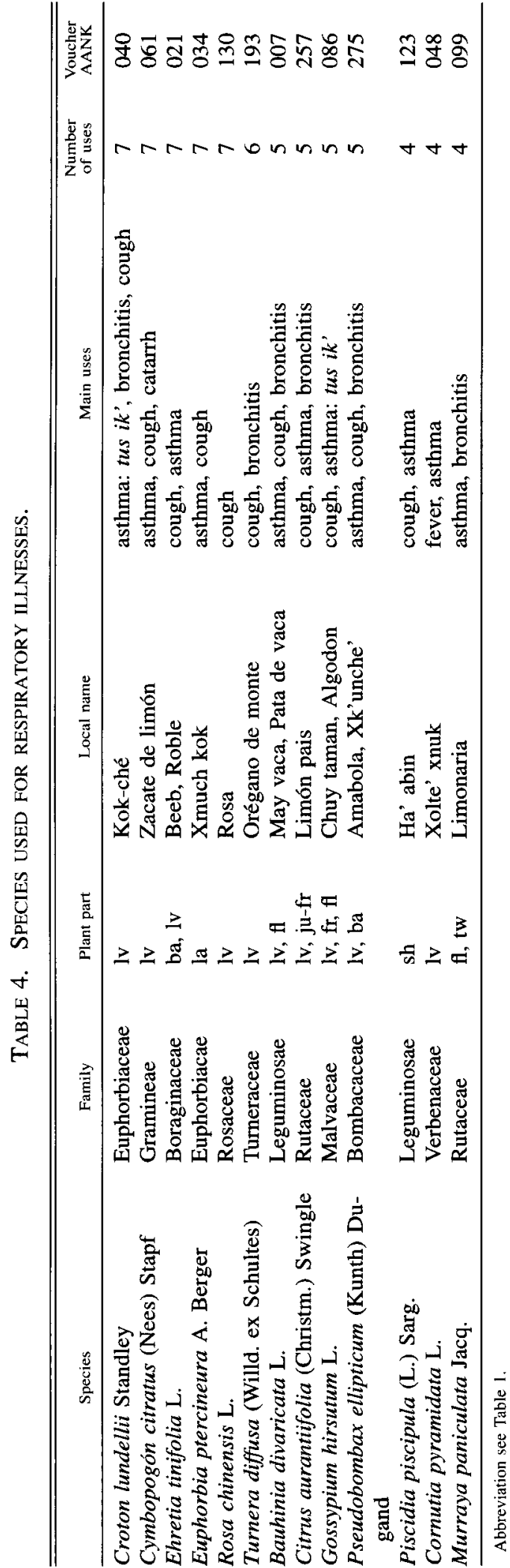

winds called tus ik'. In phytotherapy in many European countries plants rich in essential oils or in polysaccharides are regarded as useful therapies for the first two conditions ( $\mathrm{Ph}$. Helv. 8). Only Cymbopogon citratus (leaves) is known to be rich in essential oil (usually employed as a spasmolytic). The genus Ehretia is rich in rosmarinic acid, which has antiviral, antihistamine release and anti-inflammatory effects (Kuhnt et al. 1995; Simpol et al. 1994). Other important Mayan medicinal taxa are Croton lundellii (leaves), Euphorbia ptercineura (latex), Rosa chinensis (leaves) and Turnera diffusa (leaves). Some species might have moderate antibiotic effects, but there are no data to further substantiate the Mayan claims. No chemical data on these taxa are available that would substantiate the indigenous claims, but some species (Croton lundellii, Euphorbia ptercineura) might have severe side effects, because of the presence of phorbole esters.

\section{GyneCOLOGICAL UsES}

Table 5 shows the most frequently mentioned species out of 74 species with 129 use reports. Plants used during delivery are the most prominent group in this category. As described above the categorization into "hot" and "cold" illness and remedies is culturally important. Infertility of the women is regarded as a cold illness and consequently "hot" remedies (e.g., Pluchea symphytifolia) are prescribed. Infertility is considered an important problem by the healers.

Bark and leaves of Guazuma ulmifolia are used to relieve the pain of childbirth. It is one of the best known plants in the two communities and has practically no other uses. Among the Lowland Mixe it is used as a remedy for diarrhea and also for pain in the uterus and vaginal hemorrhages (Heinrich 1989), among the Isthmus Sierra Zapotecs for diarrhea and fever (Frei, Sticher, and Heinrich 1998). Polymeric proanthocyanidins are common and antisecretoric effects on cholera induced colonic secretion were reported (Hoer, Rimpler, and Heinrich 1995). No data are available to validate the therapeutic claims of the Yucatec Maya. Pluchea symphytifolia (leaves) is mostly used to "warm up the womb," for "irregular menstruation" and uterine spasms. According to the Yucatec Maya the preparation of the remedy is essential for the therapeutic effect. If an abortive effect is desired, the remedy has to be drunk while it is still 


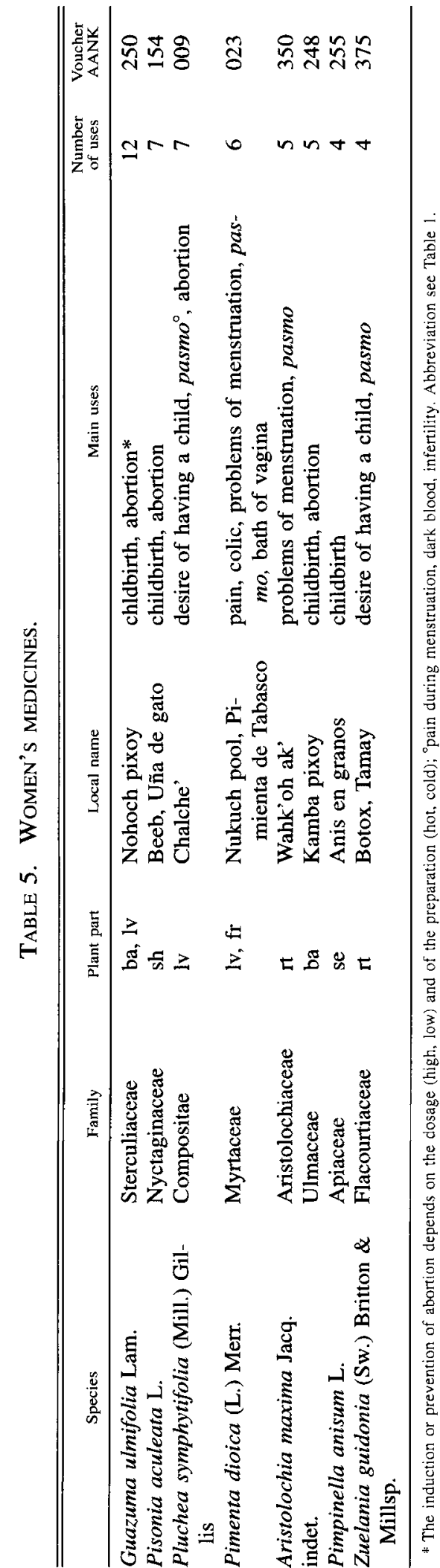

hot. For the other therapeutic uses the remedy is drunk when it has cooled down. While some data on the biological effects of the plants and on biologically active caffeoylquinic acids are available (Scholz, Heinrich, and Hunkler 1994), no information validates the traditional Mayan uses. No data are available which support the reported use for relieving pain of Pisonia aculeata.

\section{Plants Used to Counteract Venomous ANIMAL BITES AND STINGS}

In this group 44 species with 76 use-reports were documented. Most of the plants are applied topically on the wound caused by a snake or scorpion. Many persons state that the treatment of snake bites requires 16 species, but no informant listed that many taxa. Crossopetalum gaumeri is the most frequently mentioned species in this group. All informants report that immediately after the bite of a snake one should chew a piece of the drug. The powdered drug is also applied externally and/or orally as a decoction. Triterpenes of the oleanan, lupan amd friedelan type are frequently reported in the Celastraceae and also in the genus. Characteristic for the family are chinoid pigments-the celastroidswhich are derived from friedelanes. These compounds are reported to have antibacterial and cytotoxic effects (Hegnauer 1989:223). Anredera vesicaria and Urechitis andrieuxii are wound dressings. No data on antivenomous effects of any one of these species are available.

\section{URological Problems}

In Table 7, 44 species with 66 use-reports are summarized. "Kidney trouble" is mentioned most frequently, yet it does not represent a specific condition. Many of the plants may act as diuretics, the Yucatec Maya term for the illness-k'aluix - is generally explained as "the patient can't pass the urine." Also included in this group is "diabetes." The Yucatec Maya consider plants to be effective in the treatment of the latter illness if the plants act as diuretics. Malmea depressa - the most popular treatment of "kidney trouble" among the Yucatec Mayawas recently investigated phytochemically in detail for the first time and revealed the presence of phenylpropanoids (Jimenez A. et al. 1996). No data to substantiate the indigenous claims are available. 


\section{EYE REMEDIES}

In this group 39 use-reports referred to 27 species. Inflammations and disturbing, long lasting spots on the surface of the eye (buy) are frequently treated with herbal remedies. Often drops prepared from the leaf-sap of various plants are used and applied topically. No plant stands out as particularly more important than the others: Ocimum basilicum L., Chamaecrista glandulosa Greene and Desmanthus spp. are mentioned three times each, Euphorbia hirta L. and $E$. heterophylla Desf. two times. In the case of $O$. basilicum the mucilaginous seeds are used for the treatment. No attempts were made to validate the indigenous uses.

\section{OTHER USES}

The uses summarized in this group (53 species with 80 use-reports) are very diverse. But only two plants stand out as being of some importance. In most cases it is not possible or meaningful to evaluate the therapeutic claims. Piper amalago (6 use-reports) is popularly used to fight dandruff and split hair tips. No attempt was made to ascertain the therapeutic value. The rootstock of Anredera vesicaria is used for broken bones as a hard gypsum like plaster bandage.

\section{Conclusion}

This study clearly demonstrates that medicinal plants still are an important natural resource for the Yucatec Maya of Chikindzonot, Ekpetz and Xcocmil. However, biomedical pharmaceuticals are becoming increasingly popular. Such pharmaceuticals are of less importance in the area we studied as compared to other Yucatec Mayan communities. No detailed study on these forms of treatment in the Yucatec Maya area exists (van der Geest, Reynolds, and Harden 1996).

Most of the species recorded in this study have been reported as useful medicinals in other regions of Central America, Mexico and the $\mathrm{Ca}$ ribbean, but contrary to these studies we have presented data that allow the evaluation of the relative importance of a particular species in the medical system of the Yucatec Maya. The method also is useful for other culturally important plant products (e.g., dyes). It is based on interviews conducted by a single researcher, with the help of a field assistant or translator. In our previous studies with the Zapotecs and Nahua, we documented 3600 and 800 individual use-re- 
ports, respectively. (Frei, Sticher, and Heinrich 1998; Weimann and Heinrich 1997). These usereports yield relevant information on the intracultural importance of a specific plant as compared to other taxa. In a subsequent analysis the three ethnobotanical studies conducted with a similar methodology will be compared.

The quantitative data have to be seen in comparison to other types of ethnobotanical information. Garden plants are generally more important in the medical system of the Yucatec Maya than plants collected outside the community. Many informants also proudly show (newly) introduced taxa (esp. Mentha spp., also Citrus spp., Lippia alba). Consequently, in order to foment the indigenous use of medicinal plants a medicinal plant garden is being built up in cooperation with two of the three communities. Other types of information relating to the cultural importance of a plant can be drawn from the classification of plants in the indigenous system (the humoral system or systems based on organoleptic properties of plants; Heinrich 1998). Such a discussion goes beyond the scope of this paper.

Based on estimates by Bye (1993:707) 15\% or 5000 species of the Mexican flora are used medicinally. The method presented here contributes to the selection of the most important ones, which then can be studied pharmacologically, toxicologically and phytochemically in order to evaluate the indigenous claims (Robineau and Soejarto 1996). These studies will also help to revalue the indigenous uses of medicinal plants. Plants which seem to be of particular relevance for such studies are, for example, Anredera vesicaria, Dorstenia contrajerva, Diospyros anisandra, Guazuma ulmifolia and Zanthoxylum caribaeum. Studies on some of these plants are consequently under way.

An earlier version of this paper focusing on plants used in gastrointestinal medicine was presented at the symposium "Plants for Food and Medicine," July 1-6, 1996, Imperial College, London at the joint meeting of the Society for Economic Botany and the International Society for Ethnopharmacology.

\section{ACKNOWLEDGMENTS}

This research would not have been possible without the collaboration of the healers, midwives and other inhabitants of the communities we worked in, who are the traditional keepers of this knowledge. The botanical identification at CICY and MEXU was performed in collaboration with the numerous specialists at this institution. In particular we would 
like to thank Dra. I. Olmsted, Dr. R. Durán, J. Granados, P. Simá and J.C. Trejo of CICY as well as O. Tellez, R. Lira and Dr. M. Sousa of MEXU. This research owes much to the continued support of Prof. $H$ Rimpler (Freiburg), and to the help of Dra. B. Pfeiler (UADY, Mérida), Dr. Tuz (INI, Valladolid) and Dr. Baltisberger (Zürich). We are very grateful to Dr. John Plant (Freiburg) for critically reviewing the manuscript. Financial support by SDC (Swiss Agency for Development and Cooperation, Berne, Switzerland) and the SANW (Swiss Academy of Natural Sciences) is gratefully acknowledged.

\section{Literature Cited}

Aguilar, A., J. R. Camacho, S. Chino, P. Jácquez, and M. E. López. 1994. Herbario medicinal del Instituto Mexicano del Seguro Social. Instituto Mexicano del Seguro Social. México, D.F.

Alcorn, J. B. 1984. Huastec Mayan Ethnobotany. University of Texas Press, Austin.

Argueta Villamar, A. (coordinator) 1994. Atlas de las plantas de la medicina tradicional Mexicana. 3 Vols. Instituto Nacional Indigenista, México, D.F.

Arnasonn, Th., F. Uck, J. Lambert, and R. Hebda. 1980. Maya medicinal plants of San José Succotz, Belize. Journal of Ethnopharmacology 2:345-364.

Barrera Marín, A., A. Barrera Vázquez, and R. M. López Franco. 1976. Nomenclatura etnobotanica Maya. Una interpretación taxonómica. Secretaria de Educación Publica (SEP). Centro Regional del Sureste, Mérida.

Berlin, B., and E. A. Berlin. 1996. Medical Ethnobiology of the Highland Maya of Chiapas, Mexico. Princeton University Press, Princeton, NJ.

Berlin, E. A., and V. M. Jara. 1993. Me'Winik: Discovery of the biomedical equivalance for a Maya ethnomedical syndrome. Social Science and Medicine 37:671-678

Borges del Castillo, J., M. T. Manresa F., F. Rodriguez L., and P. Vasquez B. 1981. Juanislamin and 2,3-epoxy-juanislamin, two new sesquiterpenic lactones from Calea urticifolia. Journal of Natural Products 44:348-350.

Bork, P. M., M. L. Schmitz, C. Weimann, M. Kist, and M. Heinrich. 1996. Nahua indian medicinal plants (Mexico): Inhibitory activity on NF- $\mathrm{KB}$ as an anti-inflammatory model and antibacterial effects. Phytomedicine 3(3):263-269.

$\longrightarrow$ - M. Kuhnt, C. Escher, and M. Heinrich. 1997. Sesquiterpene Lactone Containing Mexican Indian Medicinal Plants and pure Sesquiterpene Lactones as Potent Inhibitors of Transcription Factor кB (NF-кB). FEBS Letters 402(1):8590.

Bye, R. 1993. The role of humans in the diversification of plants in Mexico. Pages 707-731 in T. P. Ramamoorthy, R. Bye, A. Lot and J. Fa, eds., Biological Diversity in Mexico: Origins and Distribution. Oxford University Press, Oxford.

Cáceres, A., A. V. Alvarez, A. E. Ovando, and B. S. Samayo. 1991. Plants used in Guatemala for the treatment of respiratory diseases. Journal of Ethnopharmacology 31:193-208.
Calzado, F., R. Mata, R. Bye, and E. Linares. 1990. A retrochalcone from Anredera scandens. Phytochemistry 29:2737-2738.

Cardeña Vázquez, I. 1985. Medicina tradicional en Chikindzonot, Yucatán. Cuadernos de Trabajo, Yucatán No. 10. Secretaría de Educación Publica (SEP), Dirección General der Culturas Populares, Mexico, D.F.

Comerford, S. C. 1996. Medicinal plants of two Mayan healers from San Andrés, Petén, Guatemala. Economic Botany 50:327-336.

Duch, J. G. 1988. La conformación teritorial del estado de Yucatán. Universidad Autónoma Chapingo, Centro Regional de la Peninsula de Yucatán, México, D.F.

Etkin, N., ed. 1994. Eating on the Wild Side. The Pharmacologic, Ecologic and Social Implications of Using Noncultigens. University of Arizona Press, Tucson.

Falk, U. 1992. Kladistische und chemotaxonomische Beitraege zur Stellung der Unterfamilie Caryopteridoideae Briq. innerhalb des Verbenaceae-Lamiaceae Komplexes. Dissertation. University of Freiburg, Germany.

Frei, B., O. Sticher, and M. Heinrich. 1998. Zapotec Use of Medicinal Plants: Documentation and Evaluation. Journal of Ethnopharmacology: 62:149_ 165.

Friedman, J., Z. Yaniv, A. Dafni, and D. Dalewitch. 1986. A preliminary classification of the healing potential of medicinal plants. Journal of Ethnopharmacology 16:275-287.

Girón, L. M., V. Freire, A. Alonzo, and A. Cáceres. 1991. Ethnobotanical survey of the medicinal flora used by the caribs of Guatemala. Journal of Ethnopharmacology 34:173-188.

Glasby, J. S. 1991. Dictionary of Plants Containing Secondary Metabolites. Taylor \& Francis, London.

Haensel, R., K. Keller, H. Rimpler, and G. Schneider. 1992-1994. Hagers Handbuch der Pharmazeutischen Praxis. Drogen. Springer-Verlag, Berlin.

Hegnauer, R. 1962-1996. Chemotaxonomie der Pflanzen. 14 Vols. Birkhaeuser Verlag, Basel, Boston, Berlin.

Heinrich, M. 1989. Ethnobotanik der Tieflandmixe (Oaxaca, Mexico) und phytochemische Untersuchung von Capraria biflora L. (Scrophulariaceae). Dissertationes Botanicae No. 144.. J. Cramer, Berlin, Stuttgart.

. 1992. Economic botany of American Labiatae. Pages 475-488 in R. M. Harley and T. Reynolds, eds., Advances in Labiatae Science. Richmond. Royal Botanical Gardens, Kew.

. 1996. Ethnobotany of Mexican Compositae: An analysis of historical and modern sources. Pages 475-503 in D. J. N. Hind, Editor-in Chief, Proceedings of the International Compositae Conference, Kew, 1994. Vol. 2. Biology and Utilization 
(vol eds. P.D.S. Caligaria and D.J.N. Hind). Richmond (UK). Royal Botanical Gardens, Kew.

1998. Indigenous concepts of medicinal plants in Oaxaca. Ecology of Food and Nutrition.

$\longrightarrow$, H. Rimpler, and N. Antonio B. 1992. Indigenous phytotherapy of gastrointestinal disorders in a Mixe lowland community. Journal of Ethnopharmacology 36:63-80.

$\longrightarrow$, A. Ankli, B. Frei, C. Weimann, and O. Sticher. n.d. Comparitive Ethnobotany of four Mexican Indian Groups: An Analysis. Social Science and Medicine: submitted.

Herrera Castro, N. D. 1994. Los huertos familiares Mayas en el oriente de Yucatán. Etnoflora Yucatenense No 9. Univerisdad de Yucatán, Mérida.

Hoer, M., H. Rimpler, and M. Heinrich. 1995. Inhibition of intestinal chloride secretion by proanthocyanidins from Guazuma ulmifolia. Planta medica 61:208-212.

Humphries, S. 1993. The intensification of traditional agriculture among Yucatec Maya farmers. Human Organization 21:87-102.

INEGI. 1993. Anuario estadistico del Estado de Yucatán. XI Censo general de población y vivienda, 1990. INEGI (Instituto Nacional de Estadistica del Estado de Yucatán), Mérida.

Jimenez, A., R. Mata, B. Lotina-Henssen, A.L. Anaya L., and L. Velasco I. 1996. Phytogrowth-Inhibitory Compounds from Malmea depressa. Journal of Natural Products 59:202-204.

Johns, T. 1990. With Bitter Herbs They Shall Eat It. University of Arizona Press, Tucson.

$\longrightarrow$, J. O. Kokwar, and E. K. Kimanani. 1990. Herbal remedies of Luo of Siaya District, Kenya: Establishing quantitative criteria for consensus. Economic Botany 44:369-381.

Kato, T., B. Frei, M. Heinrich, and O. Sticher. 1996. Antibacterial hydroperoxysterols from Xanthosoma robustum. Phytochemistry 41:1191-1195.

Khalid, S. A. 1983. Chemistry of the Burseraceae. Pages 281-299 in Peter G. Waterman and M.F. Grundon, eds., Chemistry and Chemical Taxonomy of the Rutales. Academic Press, London.

Koehler, U. 1990. Altamerikanistik. D. Reimer, Berlin.

Kuhnt M., A. Proebstle, H. Rimpler, R. Bauer, and M. Heinrich. 1995. Biological and pharmacological activities and further constituents of Hyptis verticillata. Planta medica 61(3):227-232.

List, P. H., and L. Hoerhammer, eds. 1969-1980. Hagers Handbuch der Pharmazeutischen Praxis. 4th. ed. 8 vols. Springer-Verlag, Berlin.

Lopez Austin, A., and C. Viesca Treviño. 1984. La Historia general de la medicina en México. Tomo I: México antiguo. Universidad Nacional Autónoma de México, México, D.F

Mendita, R. M., and S. del Amo R. 1981. Plantas medicinales del Estado de Yucatán. INIREP (Ins- tiuto Nacional de Investigaciones sobre Recursos Bioticos). Xalapa (México).

Moerman, D. E. 1996. An analysis of the food plants and drug plants of native North America. Journal of Ethnopharmacology 52:1-22.

Morales, M. A., J. Tortoriello, M. Meckes, D. Paz, and X. Lozoya. 1994. Calcium-antagonist effect of quercetin and its relation with the spasmolytic properties of Psidium guajava L. Archives of Medical Research (México, D.F.) 25:17-21.

Morton, J. F. 1981. Atlas of Medicinal Plants of Middle America, Bahamas to Yucatan. C. Thomas, Springfield, IL.

Okuda, T., Y. Takashi, T. Hatano, K. Yazaki, Y. Ikegami, and T. Shingu. 1987. Guavins A, C and D from Psidium guajava. Chemical and Pharmaceutical Bulletin 35:443-446.

Orosa Díaz, J. 1991. Historia de Yucatán. 22a reimpresión. Ediciones de la Universidad Autónoma de Yucatán. Mérida.

Pfeiler, B. 1995. Zur Prosodie des Spanischen in Yucatán, Mexiko. Pages 119-134 in Klaus Zimmermann, ed., Lenguas en contacto en Hispanoamérica. Vervuert, Frankfurt.

Pharmacopoea Helveticae 8. 1997. Eidgenšssisches Departement des Innern, Eidgenšssische Drucksachen- und Materialzentrale. Bern.

Phillips, O. L. 1996. Some quantitative methods for analyzing ethnobotanical knowledge. Pages 171197 in M. N. Alexiades, ed., Selected Guidelines for Ethnobotanical Research. A Field Manual. Advances in Economic Botany (New York) 10.

Pulido Salas, Ma. T., and L. Serralta Peraza. 1993. Lista anotada de las Plantas medicinales de uso actual en el estado de Quintana Roo, México. Centro de Investigaciones de Quintana Roo. Chetumal (México).

Redfield, R., and A. Villa Rojas. 1990 [orig. 1934]. Chan Kom: A Maya Village. Waveland Press, Inc., Illinois.

Robineau, L., and D. D. Soejarto. 1996. Tramil: A research project on the medicinal plant resources of the Caribbean. Pages 317-325 in M. J. Balick, E. Elisabetsky and S. A. Laird, eds., Medicinal Resources of the Tropical Forests. Columbia University Press, New York.

Rodriguez-Hahn, L., B. Esqivel, and J. Cárdenas. 1995. Neo-clerodane diterpenoids from American Salvia species. Pages 311-332 in J. T. Arnason, R. Mata and J. T. Romero, eds., Phytochemistry of Medicinal Plants. Recent Advances in Phytochemistry 29.

Roys, R. L. 1931. The Ethno-Botany of the Maya. The Tulane University of Louisiana, New Orleans, LA.

Salvador Flores, J., and L. Espejel Carvajal. 1994. Tipos de vegetatición de la península de Etnoflora Yucatanense, Fasiculo 3. Universidad Autónoma de Yucatán, Mérida. 
Scholz, E., M. Heinrich, and D. Hunkler. 1994. Caffeoylquinic acids and some biological activities of Pluchea symphytifolia. Planta medica 60:360-364.

Simpol, L. R., H. Otsuka, K. Ohtani, R. Kasai, and K. Yamasaki. 1994. Nitrile glucosides and rosmarinic Acid, the histamine inhibitor from Ehretia philippinensis. Phytochemistry 36:91-95.

Sosa, V., J. Salvador Flores, V. Rico-Gray, R. Lira, and J. J. Ortiz. 1985. Lista florística y sinonimia Maya. Instituto Nacional de Investigaciones sobre Recursos Bioticos (INIREB), Xalapa (México). Etnoflora Yucatenense fas. 1

Standley, J. L. 1930. Flora of Yucatan. Field Museum of Natural History, Chicago, Publication No. 279, Botanical Series Vol. 3 No. 3.

Steggerda, M., and B. Korsch. 1943. Remedies for diseases prescribed by Maya Indian herb-doctors. Bulletin of the History of Medicine 13:54-82.

Suarez, A., G. Ulate, and J. F. Ciccio. 1997. Cardiovascular effects of ethanolic and aqueous extracts of Pimenta dioica in Sprague-Dawley rats. Journal of Ethnopharmacology 55:104-111.
Terán, S., and C.H. Rasmussen.1994. La milpa de los Mayas. Universidad de Yucatán. Mérida.

Terreaux, C., M. Maillard, H. Stoeckli-Evans, M. P. Gupta, K. R. Downum, J. M. E. Quirke, and K. Hostettmann. 1995. Structure revision of a furanocoumarin from Dorstenia contrajerva. Phytochemistry 39:645-647.

Tomas Barberan, F. A., S. Z. Husein, and M. I. Gil. 1988. The distribution of methylated flavones in the Lamiaceae. Chemical Systematics and Ecology 16:43-46.

van der Geest, S., S. R. Reynolds, and A. Harden. 1996. The anthropology of pharmaceuticals: A biographical approach. Annual Review of Anthropology 25:153-178.

Villa Rojas, A. 1981. Terapéutica tradicional y medicina moderna entre los Mayas de Yucatán. Anales de Antropología (México, D.F.) 18(2):13-28.

Weimann, C., and M. Heinrich. 1997. Indigenous medicinal plants in Mexico: The example of the Nahua (Sierra de Zonglicia). Botanica Acta 110: 62-72.

\section{BooK REviEW}

Tropical Mycology. K. K. Janardhanan, C. Rajendran, K. Natarajan, and D. L. Hawksworth (eds).1997. Science Publishers, Inc. P.O. Box 699, Enfield, NH 03748. xviii +315 pp (hardcover). \$89. ISBN 1886106-63-0.

With a very attractive title, Tropical Mycology, a group of mycologists, colleagues and former students of Prof. C.V. Subramanian, celebrate his 70th birthday and a prolific career devoted to the study of the Hyphomycetes. This distinguished scientist is eloquently introduced in the Foreword by David L. Hawksworth (Director of the International Mycological Institute, United Kingdom). A detailed biography of Prof. Subramanian is collectively signed by The Editors.

Thirty-seven mycologists are the authors of twenty articles covering topics ranging from the inventory of fungal biota to subcutaneous mycoses in tropical and some subtropical landscapes. It is only appropriate that the predominance of treatments are on Hyphomycetes, but all the contributions are concisely written and most of them well illustrated.

For the neotropical fungologist two papers are of particular interest-Guzman et al. "An overview on the tropical fungi from Mexico," and I. Kalyanasundaram's "Myxomycetes in the Tropics: distribution and ecology." The first contribution in the collection is Jean-Marc Moncalvo on "Evaluation of fungal diversity in the Tropics: systematics perspectives." This material, of great general interest, is a comprehensive summary of recent knowledge. Moreover, the chapter provides a good introduction to the potentiality of molecular biology in elucidating fungal phylogenies.

The price will make the book inaccessible to many students and researchers in tropical areas. Moreover, the predominance of Hyphomycetes in this volume will destine it for the specialist in that group of fungal organisms.

Luis Diego Gomez

Estacion Las Cruces \& Wilson Botanic Garden P.O. Box 73-8257 Coto BRUS, Costa RICA 